\title{
Interactive comment on "Plants or bacteria? 130 years of mixed imprints in Lake Baldegg sediments (Switzerland), as revealed by compound-specific isotope analysis (CSIA) and biomarker analysis" by $M$. Lavrieux et al.
}

\section{Lavrieux et al. \\ axel.birkholz@unibas.ch}

Received and published: 19 September 2018

Thank you for your valuable comments and suggestions. Regarding point 1, we agree with the reviewer to add a correction of the lake sediment isotopical data for the Suess effect. In a revised version we propose to show the corrected values next to the original ones. The correction also has to be applied to the source soil samples. However, the sampled soil organic matter consists of a mixture of different (unknown) ages, from recent production to a few hundred years. A side by side comparison of values with and without Suess correction might eliminate our hypothesis to explain the depleted

Printer-friendly version

Discussion paper 
d13C values of the fatty acids in the older sediments with the Suess effect.

Regarding point 2.1: We thank the reviewer for his possible explanation of our ob-

servation. Marlène Lavrieux, who did all the preparative work with the lake sediment samples has experience in the work with chironomid larvae and is convinced that there were neither complete organisms nor residues of chironomid larvae present in the lake sediments. Further we checked the cited literature (Makhutova et al. 2017) and could only find documentation of production of saturated long-chain fatty acids up to chain length of $22 \mathrm{C}$-atoms by chironomidae. Is there any reference we might have overlooked where it is shown that chironomid larvae are able to produce fatty acids longer than C22:0 in significant amounts?

Due to the extreme eutrophication history of the lake and changing bacterial communities we cannot exclude that there might have been bacteria present with the ability to produce long-chain fatty acids. Depletion of long-chain fatty acid $13 \mathrm{C}$ values in marine sediments was described as being a possible result of a mixture of terrestrial produced fatty acids and depleted in-situ produced bacterial long chain fatty acids in an anoxic environment (Gong and Hollander, 1997; Teece et al., 1999 (d13C depletion of short/mid-chain fatty acids after production under anoxic conditions by marine bacteria), Fang et al., 2014). In a revised version of the manuscript we will discuss this hypothesis in more detail. But this would not really change the conclusion of our study: that the activity of bacteria would alter our isotope signals.

However, we discussed further options and we will also include a discussion about common reed (phragmites australis) in the riparian zone as a possible additional source. Photosynthesis of Phragmites with $\mathrm{CO} 2$ derived from oxidized methane could be an optional source for depleted long-chain fatty acids (cf. Alewell et al. 2011, d13C depletion of mosses, induced by photosynthesis with methane derived $\mathrm{CO} 2$, effected the bulk carbon d13C in Scottish bog). It is well possible that along with the intensification of agriculture in the catchment the presence of phragmites in the riparian area was decreasing. This could be an explanation for the depleted values until world war two.

Printer-friendly version

Discussion paper
Interactive comment

2 
With the absence (very low stock left) of phragmites also the influence of a depleted source of the fatty acids would have disappeared. Further we will obtain more detailed information on the land use history over the last 150 years such as to provide a better basis for the discussion

Regarding point 2.2: We choose the long-chain fatty acids C24:0-C30:0 because they are mainly produced by higher plants and other known producers (bacteria cf. literature in the manuscript) were not identified in Lake Baldegg so far. Short- and mid-chain fatty acids are also produced by bacterial and aquatic organisms. In a lake environment we expect increased production of these sources for the short- and mid-chain fatty acids in addition to the higher plants, which would heavily impede the sediment apportionment. Therefore, we concentrated on the long chain ones. 2.3: In the same study also suspended sediments were sampled and the sample amount was not enough to do additional analysis for bulk carbon. The same was true for the lake sediment samples. Due to the high temporal resolution, all material was used for lipid extraction.

C.R. Gong, D.J. Hollander, Differential contribution of bacteria to sedimentary organic matter in oxic and anoxic environments, Santa Monica Basin, California Org Geochem, 26 (1997), pp. 545-563.

M.A. Teece, M.L. Fogel, M.E. Dollhopf, K.H. Nealson Isotopic fractionation associated with biosynthesis of fatty acids by a marine bacterium under oxic and anoxic conditions Org Geochem, 30 (1999), pp. 1571-1579.

Jidun Fang, Fengchang Wu, Yongqiang Xiong, Fasheng Li, Xiaoming Du, Da An, Lifang Wang, Source characterization of sedimentary organic matter using molecular and stable carbon isotopic composition of n-alkanes and fatty acids in sediment core from Lake Dianchi, China, Science of The Total Environment, Volumes 473-474, 2014, Pages 410-421.

Alewell, C., Giesler, R., Klaminder, J., Leifeld, J., and Rollog, M.: Stable carbon isotopes as indicators for environmental change in palsa peats, Biogeosciences, 8, 1769-

Printer-friendly version

Discussion paper 
1778.

Interactive comment on Biogeosciences Discuss., https://doi.org/10.5194/bg-2018-288, 2018.
BGD

Interactive

comment 